\title{
STUDIES ON STORING POTATO TUBERS OUT REFRIGERATOR USING NATURAL ESSENIAL OILS: \\ (A) IMPROVING STORABILITY AND REDUCING OF AMBIENT TEMPERATURE STORAGE PROBLEMS.

\author{
El-Sayed Hala A.*; E.L. El-S. Fathy**; Rawia E. Ibrahim and \\ Amal A. El-Awady \\ * Veget.Dept., Fac.of Agric., Mansoura Univ . \\ * *Vegt.Dept ., Hort . Res. Inst ., Agric . Res. Cent.,Cairo , Egypt .
}

\begin{abstract}
Storage experiments were conducted at El-Barmon, Horticulture Research Institute during 2003 and 2004 In order to study the effect of different storage treatments, i.e anise, mint, fennel, eucalyptus oils (individuals or paris) / ambient temperature added to cold storage treatment on storability and bioconstituents of tubers (saved from summer harvesting) of two potato cvs (Diamant and spunta ) during 9 months storage period .

The results could be summarized as follows :-

1 - Diamant and spunta cvs were significantly differed in their effect on sprouting , weight loss and damage percentages as well as sprout length. Tubers of Diamant cv were of significant lower values also those were of higher carbohydrate, starch, non reducing sugars and total phenols content .

2 - The most superior storage treatments which completely $(100 \%)$ suppressed sprouting and damage incidence and greatly reduced weight loss percentage were of mint oil and anise + mint oils .

3 - Treated tubers of both cvs with all essential oils / ambient temperature storage and those that kept on cold $\left(4^{\circ} \mathrm{C}\right)$ were significantly maintained better storability and greatly preserved their bioconstituents compared with untreated ones. The most superior ones, which completely $(100 \%)$ suppressed sprouting and damage percentage and greatly reduced weight loss percentage, were mint oil and anise + mint oil treated tubers of both cvs (with no significant differences among them ). Also, $4^{\circ} \mathrm{C}$ stored tubers and fennel oil treated tubers of Diamant were the following superior treatments.
\end{abstract}

\section{INTRODUCTAION}

Potato (Solanum tuberosum, L.) known as an important vegetable for local consumption and exportation. It is produced in Egypt in Nili and summer seasons, but it extensively consumed during the whole year.

Sprouting, weight loss, rotting and microbial decay represent an serious problems arise during storage of potatoes in Nawalla and/or refrigerator $\left(10^{\circ} \mathrm{C}\right)$. In most cases some synthetic sprout suppressants commonaly used but they evolved serious toxological risks healthy cautioned cautioned and severely impair and viability ( Hartmans et al ., 1995 and Daniels et al ., 1996 ) .

Generally, cold storage known as a common practices to minimize such problems, but it is of high cost and sometimes of insufficient storage capacity .Elucidation of ambient temperature storage conditions as a high 
temperature stressful factor induce generation of elevated levels of the toxic and degradable reactive oxygen species (ROS) (Internal injurious oxidative stress) within stressed tissues (Cakmak and Marschner, 1992 and Bowler et al., 1992) . gave more attention for new investigation and technique in potato storage .

Recently, some natural essential oils and/or their major components (monoterpenes) used and proved efficient sprout suppressive and antimicrobial actions (Oosterhaven et al., 1993 and Hartman et al., 1995 ,Rojas 2000 , Fathy et al., 2005 ).

Present work aimed to study the effect of monoterpenes and antioxidants rich essential oils (anise, fennel, mint and eucalyptus) and their combinations during ambient temperature storage Spunta and Diamant to reduce the previous mentioned problems.

\section{MATERIALS AND METHODS}

Long term storage experiment of Potatoes were conducted at ElMansoura Research Laboratories, Horticulture Research Institute, during 2003 and 2004.

These experiments were performed to study effect of hydro distillated essential oils, of mint, fennel, anise and eucalyptus applied to tubers of Spunta and Diamant [ single $(5 \mathrm{~m} / \mathrm{L})$ ] , [ pairs $(2.5+2.5 \mathrm{~m} / \mathrm{L})$ ] and all oils ( $1.25 \mathrm{~m} / \mathrm{L}$ ) of each one, added to the control one ( ambient temperature storage without oil application ) and cold storage $4^{\circ} \mathrm{C}$ on their morphological and biochemical behavior. Tubers of spunta and Diamant cvs were saved from the summer crops of 2003 and 2004, cured for 15 days . Then stored in pile under thick layer of rice straw of $50 \mathrm{~cm}$ height on a April 25 in 3 vertical rows (replications), each one included 12 pile $(25 \mathrm{~kg}$ of tubers) for each potato cv. The surface of rice straw cover was frequently moisted with water during the whole storage period. These tubers were sprayed 3 times with emulsion of different essential oils, this began as onset of storage, and again at 3 months intervals.

\section{The experimental design and treatments :}

Split plot design with three replications was adopted main plot occupied with two potato cvs Spunta and Diamant. While, sub plot occupied with 13 treatments ( 11 treatments of essential oils / ambient temperature + cold storage ( $4 \mathrm{OC}$ ) + control (ambient temperature storage without any treatment .

\section{Studied characters}

Sprouting (\%):,Sprout length , Weight loss , and Damage (\%), were measured according to El Wady 2002 were determine after 3,6 , and 9 months from the beginning of storage :

Chemical analysis of the stored tubers :

(Sugars, carbohydrates, Starch, total free amino acids, total phenols. Those were determined at harvest and the end of storage according to methods of James (1995), Burton (1948), Jayaraman , (1985), Daniel and Goerge (1972) respectively . 


\section{RESULTS AND DISCUSSION}

Storage experiments:

Sprouting, weight loss and damage:

Effect of potato cultivars:

It was obvious from Data in (Table 1) that, sprouting, weight loss and damage \% of the two potato cvs increased with time during storage . Also, that Diamant cv maintain lower sprouting $\%$ weight loss $\%$ and damage \% during the whole storage period. Meanwhile, the stored tubers of the two cvs showed similar response and fashion regarding sprout length at different storage periods.

Also, it was evident from this data that at the third least 3 months (after 9 months ) tubers of Diamant cv were of significant lower sprouting, weight loss and damage percentage, also of shorter sprout length than those of Spunta cv in both seasons. Such results were in accordance with the results of Fathy et al. (2005).

The pronounced better storability performance of Diamant cV compared with Spunta one could be logically true under present work conditions, since the former maintained higher carbohydrate, starch and total phenols content in it's tubers (Table 5 ). This indicated that such cv might be own an active mechanism by which it slow down or inhibit the activity of the degradable and respiratory enzymes.

\section{Effect of storage treatments}

Data in (table 2) indicated that, all the essential oils treatments (ambient temperature storage) and cold $\left(4^{\circ} \mathrm{C}\right)$ storage greatly suppressed the incidence of sprouting, weight loss and damage. Also, significantly shortened the length of the sprout compared with those of the control one in the two seasons.

The same data showed that during the second 3 months, of storage only tubers of mint and anise + mint oils stile in dormant case , whereas the sprouting percentage of other treatments showed slight increase relative to their sprout case in the other prior storage during the first three months .

The same data cleared also that, at the end of storage (after 9 months of storage ) treatments of mint oil $(5 \mathrm{ml} / \mathrm{L})$ and anise + mint oils $(2.5+$ $2.5 \mathrm{ml} / \mathrm{L}$ ) have been fully (100\%) inhibited bud development and incidence of sprouting, and tuber decay also greatly reduced weight loss incidence and fully prevented compared with the other treatments in both seasons.

It was also observed that, fennel oil $(5 \mathrm{ml} / \mathrm{L})$ and cold storage $\left(4^{\circ} \mathrm{C}\right)$ followed by anise + eucalyptus oils $(2.5+2.5 \mathrm{ml} / \mathrm{L})$ and fennel + eucalyptus oils were effectively but not completely suppressed sprouting, weight loss and damage incidence of their tubers also highly reduced the length of the emerged sprout during both seasons. 
El-Sayed Hala A. et al.

1

2986 
J. Agric. Sci. Mansoura Univ., 32 (4), April, 2007 
El-Sayed Hala A. et al.

Similar results were obtained by, El-Awady (2002), and Fathy et al. (2005) (essential oils) (Cold storage)

In addition the inhibitional effect of these oils on damage (decay and rotting) of potato tubers was confirmed by findings of ; Basilico and Basilico (1999) .

They explained such effects based on the antimicrobial action of the essential oils monoterpenes and phenols content. In this connection, high temperature known to induce serious internal oxidative stress, accumulation of toxic and degradable levels of the reactive oxygen species (ROS) (H2O2, $\mathrm{OH}, \mathrm{O} 2)$. Those known to be induce the incidence of internal disturbances and dramatic events, induced membrane breakdown, extreme permeability and solutes leakage, high respiration and depletion of carbohydrate pools within the stressed tissues (Bowler et al., 1992 ; Rojes 2000) .

\section{Effect of interaction}

As illustrated in Tables ( 3 and 4$)$, this data cleared that treated tubers of both cvs with all essential oils / ambient temperature storage and those that kept at cold $\left(4^{\circ} \mathrm{C}\right)$ storage were significantly maintained better storability than untreated ones during the two seasons.

The same data proved that, at the third three months among all interaction treatments mint oil $(5 \mathrm{ml} / \mathrm{L})$ and anise + mint oils $(2.5 \mathrm{ml} / \mathrm{L}$ of each oil ) were the most potent ones, they have been fully inhibited sprouting and damage incidanca of the tubers of the two CVS .

It was also noticeable that fennel oil treatment and cold storage one showed considerable reducible effect, but not at the same potency on the mentioned characters of stored tubers for the two cvs with no pronounced differences among them in the two seasons.

Herein, these advantages effects of the interaction treatments could be attributed with their similar effect in preservation of their tubers internal bioconstituents, i.e. carbohydrate, sugars and amino acids, protection against high temperature oxidative stressful storage conditions via their tubers high phenols content .

Accordingly, induced an internal protective and preserved case of minimum biochemical changes and prolonged dormancy status.

On the other hand, such effects are logically true based on the similar effects and responses of the individual storage treatments and cvs as previously shown.

\section{Bioconstituents \\ Effect of potato cultivars}

Data in Tables ( 5 ) indicated that, tubers of Diamant cv were of significant higher carbohydrate, starch and total phenols content and lower total sugars, reducing sugars and total free amino acids than those of Spunta tubers in both seasons.

It was evident from the same data that, Diamant was of significant higher non-reducing sugars than Spunta only at the first seasons. 
J. Agric. Sci. Mansoura Univ., 32 (4), April, 2007

T3

2989 
El-Sayed Hala A. et al.

4 
J. Agric. Sci. Mansoura Univ., 32 (4), April, 2007

5

2991 
Under present storage conditions, it might be suggested that, Diamant cv. Impose an certain potential ability to preserve its carbohydrate and starch content against the degradable effect of high temperature stress and its probable inducible oxidative one (Bowler, 1992; Cakmac and Marschner, 1992 and Rojas et at., 2000).

Since, it had the considerable high total phenols content, those which known to be related with the antioxidantal protective responses Guilleea et al., 1996), catalyzed the enzymatic breakdown of the toxic ROS (ROS-scavenging) (Deans et al., 1993). Thereby, suppressing the oxidative stress destructive effects and its degradation consequences.

\section{Effect of storage treatments}

Data in (Table 6) illustrated that, all storage treatments significantly superiored the control one in their tubers bioconstituents, i.e. total carbohydrates, starch, total sugars, reducing sugars, non-reducing sugars, total free amino acids and total phenols during the two seasons. It was clear from such data that, among them tubers of (anise + mint) oils followed by mint oil were of the highest carbohydrate, starch, non-reducing sugars and the former followed by the later for the highest phenols content. At the same time, these treatments maintain low content of reducing sugars and amino acids relative to others in the two seasons.

Also, It was observed that , tubers of cold $\left(4^{\circ} \mathrm{C}\right)$ storage were of the highest significant reducing and total sugars content in the two seasons.

The present results and interpretations confirmed by those obtained by, Barakat (1996) and Fathy (2005).

Herein, of interest to compare the present ( at the end of storage ) bioconstituents values of potato tubers as affected by different treatments with those of the control one and with their initial biochemical analysis (bioconstituents). This greatly confirmed the potency of such treatments in preservation and maintenance of the stored tubers reserves, keeping the internal biochemical enzymatic activities in minimum level and in more stable case , thereby prolonged their dormancy case.

Also, proved that, these treatments were highly effective in protection of their tubers against the known degradable effects of higher temperature / oxidative stressful storage conditions.

In similar to the findings of Davies (1990), Trevanion and Kruger (1991). Whom indicated that essential oils and/or their basic constituents slowing down the activity of carbohydrates and protein breakdown associated enzymatic systems as well as respiration and energy metabolism enzymes.

Generally, the pronounced preserved effects of the applied individual oils or some of their combinations (pairs) on the bioconstituents of their treated tubers during their long term ambient temperature storage .

These effects could be greatly attributed with the known suppressive action of their major components (monoterpens and antioxidant), those which known to inhibit the activity of the internal biochemical reactions and the oxidative stress attributes of potato tubers (Herrman et al., 1996). 
J. Agric. Sci. Mansoura Univ., 32 (4), April, 2007

6

2993 
On the other hand, the marked inducible effect of cold storage on the accumulation sugars totals sugars, reducing sugar may be explained based on conversion of sucrose to glucose and fructose via invertase in cold storage results from the inactivation of an invertase inhibitor.

In contrary, control treatment which showed a dramatically degradation and depletion in its tubers carbohydrates and other bioconstituent could be explained based on the harmful and degradable effects of high temperature / oxidative stress. Such case might be induced generation of elevated toxic level of oxygen radicals (Bowler et al., 1992 and Cakmac and Marschner, 1992 ; Rojas , et al 2000) within stressed tissues. Thereby, degraded the cell membranes and allowed more $\mathrm{O} 2$ diffusion, raised respiration rate and sugars depletion (Daniels et al., 1996 ).

So, long term ambient temperature storage of control tubers resulted in extreme reduction in all internal bioconstituents relative to the initial content (Table 6 ) and relative to other treatments.

\section{Effect of interaction}

Data in (Tables 7and 8) illustrated that, all the applied essential oils and low temperature treatments were greatly preserved the bioconstituents during the long term storage of Spunta and Diamant tubers compared with those of untreated tubers in both seasons. Such data revealed that mint oil and (anise + mint) oils applied into Diamant tubers with no differences between them followed by the same oils applied into Spunta tubers respectively gave the highest significant carbohydrates content. Also, those followed by cold $\left(4^{\circ} \mathrm{C}\right)$ storage with the first $\mathrm{CV}$ then with the second $\mathrm{cv}$ respectively at the two seasons.

It was clear from the same data that the same interaction treatments and others (individuals and/or pairs) exhibit the same superior preserved effect on starch content of both cvs tubers. Mint oil and anise + mint oils applied into Diamant tubers gave the highest significant starch content (with no significant differences among them) in the two seasons. Whereas, tubers of control treatments of both cvs were of the lowest starch content.

Absolutely, the highest significant reducing sugars values were of Spunta tubers stored on $\left(4^{\circ} \mathrm{C}\right)$ followed by those of the same cv stored on ambient temperature and treated with (eucalyptus + mint) oils and by those of Diamant tubers stored on $\left(4^{\circ} \mathrm{C}\right)$ in both seasons.

Regarding non-reducing sugars, mint oil followed by anise + mint oils applied into Spunta tubers resulted in the highest significant content (all were significantly differed). The same storage treatments in the same order, when applied into Diamant tubers were the following ones and also of noticeable high non-reducing sugars in both seasons. This reflected and confirmed their potent suppressive effect on the enzymatic changes of sugars (Vander Plas, 1987; Davies, 1990; El-Wady et al., 2002 and Fathy et al., 2005).

In contrary, low temperature storage treatment, which induced the highest values of reducing sugars, maintain in the same time the lowest nonreducing sugars content of the two cvs . 
J. Agric. Sci. Mansoura Univ., 32 (4), April, 2007 
El-Sayed Hala A. et al.

8

2996 
Meanwhile, tubers of Diamant $\mathrm{cv}$ showed similar response to the same storage treatments and gave high content of total sugars relative to other treatments in both seasons.

On the other hand and dealing with amino acids content, anise + fennel + mint + eucalyptus oils $(1.25 \mathrm{ml} / \mathrm{L}$ of each one) applied to Spunta tubers, mint + eucalyptus applied to Diamant tubers, mint + eucalyptus oils applies to Spunta tubers, respectively were of the significant highest values for amino acids in the two seasons .

Meanwhile, these treatments corresponded such beneficial effects with other advantages of full sprouting inhibition and minimum values of weight losing and damage (Tables 3 and 4 ).

In similar trend, the essential oil / ambient temperature and low temperature treatments mostly maintain the same superiority in their effect on total phenols content of their tubers. Among those, mint oil and anise + mint oils (with no significant differences among them) followed by low temperature gave the highest significant total phenols in Diamante tubers (first season). Whilst, at the second season anise + mint oils followed by mint oil and by low temperature with Diamant cv were of the highest content, respectively. Meanwhile, the same treatments maintain the same effect and trend with the other potato $\mathrm{cv}$ in the two seasons.

Reversely, it was clear that, mint oil and anise oil combined with mint oil when applied either to Spunta or Diamant tubers, showed reduced values for reducing sugars and amino acids ( 7.33 and 116.5$)$ and( 7.13 and 119.65) (Spounta), (5.72 and 112.5) and (5.50 and 114.6) for Diamant mean of the two seasons, respectively. This lead to suggestion that these essential oils / ambient temperature treatments especially with Diamant cv were of great importance to be used for storing of potato tubers to obtain the best processing quality.

Finally, it could be recommend with spraying potato tubers of ( Diamant cv ) with mint oil ( $5 \mathrm{~m} / \mathrm{L}$ ) or anise + mint oils $(2.5 \mathrm{~mL}+2.5 \mathrm{~m} / \mathrm{L}$ ) 3 times during 9 months storage efficient natural, safety and const effective technique for processing and fresh consumption storage .

Also, it could be recommended with spraying potato tubers of Diamant and Spunta with fennel oil $(5 \mathrm{~m} / \mathrm{L})$ or anise oil combined with eucalyptus oil ( $2.5+2.5 \mathrm{~m} / \mathrm{L}$ ) , 3 times during long term storage / ambient temperature as better natural , safety and cost effective technique for storing potato tubers from summer yield to be used as local seed for obtaining satisfactory yield in the subsequent summer season .

\section{REFERENCES}

Barakat, M.A.S. (1996). Storability and productivity of Nili potato seed in relation to paclobutrazol (PP333). Menofiya J. Agric. Res., 21(1):135147.

Basilico, M.Z. and J.C. Basilico (1999). Inhibitory effects of some spice essential oils on Aspergillus ochraceus NRRL 3174 growth and ochratoxin a production. Letters in Applied Microbiology, 29:238-241. 
Biemelt, S.; M. Hajirezaei; E.L. Hentschel and V.W.E. Sonnewald (2000). Comparative analysis of abscisic acid content and starch degradation during storage of tubers harvested from different potato varieties. Potato Res., 43:371-382.

Bowler, C.; M.V. Montogu and D. Inze (1992). Super oxide dismutase and stress tolerance. Ann. Rev. Plant Physiol. Plant Mol. Biol., 48:233-250

Burton, W.G. (1948). The Potato. Chapman and Hall, London, P. 319.

Cakmak, T. and H.Marschner. (1992): Magnesium deficiency and high light intensity enhance activities of super oxide dismutase, ascorbite peroxidase and glutathione rereductase in bean leaves. Plant Physiol .,98:1222-1227.

Daniel, H.D. and C.M. George (1972). Peach seed dormancy in relation to indogenous inhibitors and applied growth substances. J. Amer. Soc. Hort. Sci., 97:651-654.

Daniels, L.B.J. ; R.K. Prange ; W. Kalt ; G.L. Liew; J. Walsh; P. Dean and R. Coffin (1996). The effects of ozone and 1, 8-cineole on sprouting, fry color and sugars of stored Russet Burbank potatoes. Amer. Potato J., 73:469-481.

Davies, H.V. (1990). Carbohydrate metabolism during sprouting. Amer. Potato J., 67:815-827.

Deans, S.G.; R.C. Noble ; L.Penzes and S.G. Imer 1993. Promotional effects of plant volatile oils on the poly unsaturated fatty acid statues during ageing . (In Press. (

El-Awady, A.E.A. (2002). Studies on potato storage. M.Sc. Thesis, Agric. College, Mansoura Univ.

Fathy, El-S.L.; A.M. Safa and A.E. Amal (2005). Using of natural antioxidants for improving storability of potatoes. The 6th Arabian Conference for Horticulture, Ismailia, Egypt.

Guilleen, M.D. and M.J. Manzanos (1996). A study of several parts of the plant Foeniculum vulgare as a source of compounds with industrial interest. Food Res. Inter., 29(1):85-88.

Hartmans, K.J.; P. Diepenhorst; W. Bakker and L.G.M. Gorris (1995). The use of carvone in agriculture: Sprout suppression of potatoes and antifungal activity against potato tuber and other plant diseases. Industrial Crop and Products, 4:3-13.

James, C.S. (1995). Analytical Chemistry of Food. Blokie Academic \& Proffesional, London.

Oosterhaven, K. ; K.J. Hartmans and H.J. Huizing (1993). Inhibition of potato (Solanum tuberosum) sprout growth by the monoterpene s-carvone : reduction of 3-hydroxy-3-methylglutaryl coenzyme A reductase activity without effect on its mRNA level. J. Plant Physiol., 141:463-469 .

Oosterhaven, K.; K.J. Hartmans and J.J.C. Scheffer (1995a). Inhibition of potato sprout growth by carvone enantiomers and their bioconversion in sprout. Potato Res., 38:219-230.

Rojas, J.A.; F. Dejaegher; M. Abdalla-Kotb and D.V. Jardin (2000). Expression and activity of antioxidant enzymes during potato tuber dormancy. Potato Res., 43:383-393. 
Trevanion, S.J. and N.J. Kruger (1991). Effect of temperature on the kinetic properties of pyrophosphate: fructose 6-phosphate phosphotransferase from potato tuber. J. Plant Physiol., 137:753-759.

Van der Plas. L.H.W., 1987. potato tuber storage : biochemical and physiological changes . In : Bajaj, Y.P.S. (Editor)Biotechnology in Agriculture and Forestry. Vol. 3 : potato, springerverlag Berlin Heidelberg . pp.190-135.

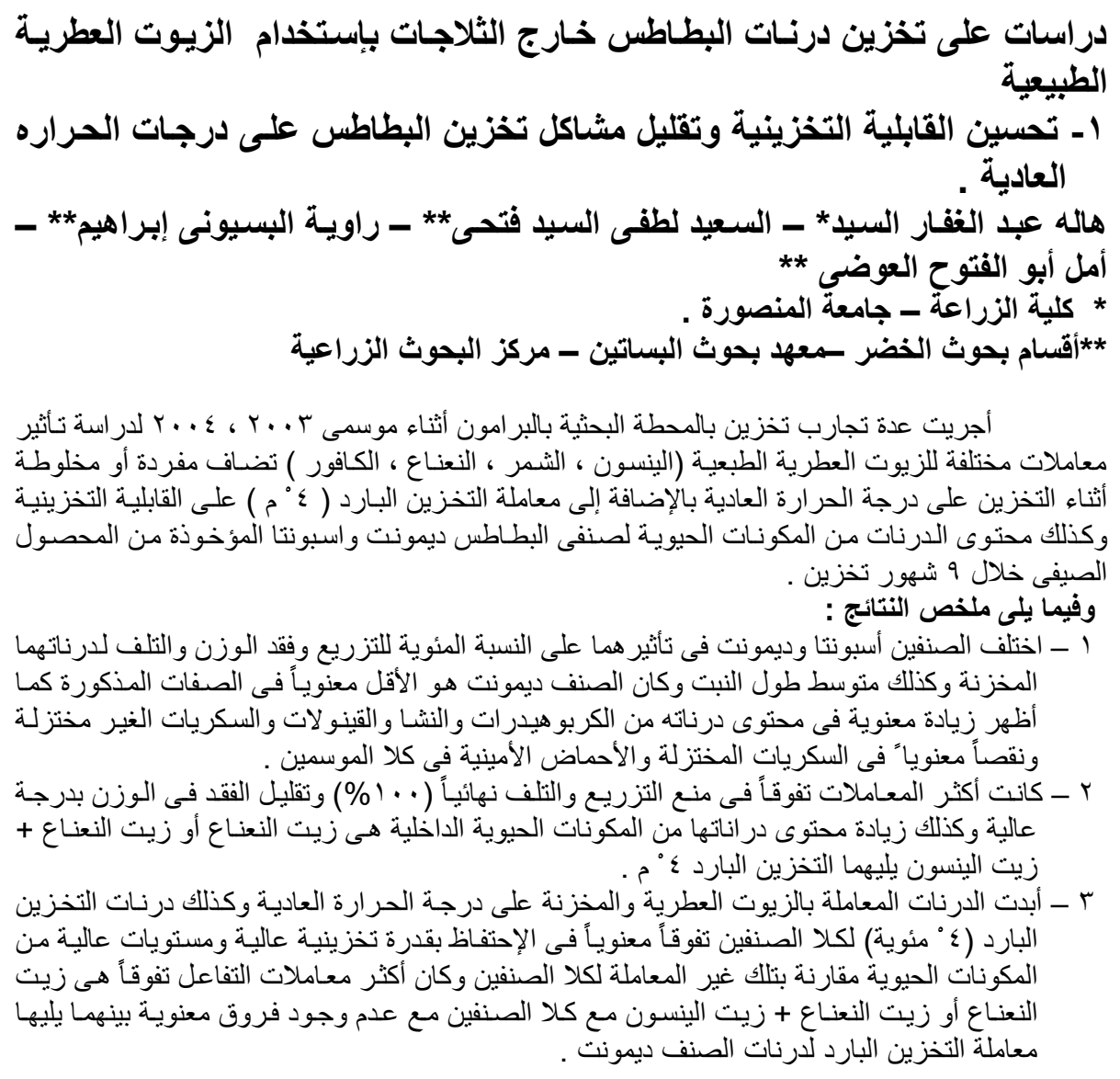


El-Sayed Hala A. et al. 